\title{
Peran Guru dalam Pengoptimalan Potensi Emosi Anak terhadap Peningkatan Kreativitas Ekspresi pada Pembelajaran Seni Rupa di SD Kota Semarang
}

\author{
Mujiyono $^{1}$, Eko Haryanto ${ }^{2}$, Gunadi ${ }^{3}$ \\ Jurusan Seni Jurusan Seni Rupa, Fakultas Bahasa dan Seni, Universitas Negeri Semarang, \\ Jl. Raya Sekaran Gunungpati Semarang 50229, Indonesia \\ ${ }^{1}$ mujiyonosenirupa@mail.unnes.ac.id, ${ }^{2}$ ekoharyanto@mail.unnes.ac.id, ${ }^{3}$ gunadi_pwd@mail.unnes.ac.id.
}

\begin{abstract}
Semua emosi dapat dipandang sebagai sumber informasi dan potensi untuk pemikiran dan produksi kreatif, tergantung pada keterampilan seseorang dalam mengenali, memahami, dan menyalurkan emosi-emosi itu secara efektif. Tujuan penelitian untuk menyelidiki metode pembelajaran dan hasil pembelajaran seni rupa yang dilakukan guru sekolah dasar di Kota Semarang dalam upaya mengoptimalkan kecerdasan emosional anak agar berperan menghasilkan kreativitas artistik. Pendekatan penelitian adalah deskriptif kualitatif yang bersifat eksplanatoris. Desain penelitian yang dipilih adalah studi kasus pada sekolah yang berkategori prestasi baik dengan melibatkan beberapa sekolah di wilayah yang berbeda dengan permasalahan atau unit analisisnya yang sama. Lokasi penelitian di SD Negeri Kota Semarang. Teknik pengumpulan data adalah wawancara, observasi, dan dokumentasi. Teknik analisis data menggunakan tahapan reduksi data, sajian data, dan diakhiri dengan penarikan simpulan. Hasil penelitian menujukkan hal-hal sebagai berikut. Pertama, guru menggunakan strategi pendekatan inspiratif melalui stimulasi individual dan klasikal untuk membangunkan dan memperdalam pengalaman emosional rutin maupun isidental hingga perasaan anak tersentuh agar kreativitas gambar terbentuk melalui pengoptimalan potensi emosi siswa. Peranan ini dapat dimainkan guru, baik pada saat awal ataupun proses pembelajaran khususnnya saat menggambar sedang berlangsung. Guru meminta siswa berekpresi pada gambar dengan tema bebas berdasarkan pilihan siswa dengan alat atau crayon. Kedua, gambar yang dihasilkan siswa menunjukkan kecenderungan kreativitas siswa yang baik, terlihat tema yang bervariasi mulai, suasana liburan, cita-cita, orang yang disayang, keceriaan, kegiatan yang disukai, lingkungan alam dan sebagainya. Corak gambar relatif sama yaitu representatif namun belum menunjukkan tingkat realistik yang sempurna. Selain itu, bentuk figur/subjek, warna, goresan garis yang bervariasi, kuat dan spontan.
\end{abstract}

Kata kunci: emosi, kreativitas, seni rupa, sekolah dasar

\section{The Role of Teachers in Optimizing Children's Emotional Potential towards Increasing Creativity Expression in Learning Visual Arts in Elementery Scholl Semarang City}

All emotions can be viewed as sources of information and a potential for creative thought and production, depending on one's skills in recognizing, understanding, and channeling them effectively. This research was conducted to investigate the strategy mechanism or visual arts learning methods carried out by elementary school teachers in the city of Semarang in an effort to optimize children's emotional intelligence in order to play a role in producing artistic creativity and to determine the quality of children's drawing creativity as a result of art learning that has been carried out by a teacher. The research approach is descriptive qualitative and explanatory. The research design is a case study in schools with good achievement categories involving several schools in different areas with the same problem or unit of analysis. Data collection techniques are interviews, observation, and documentation. The data analysis technique uses the stages, reduction, display and verification. The results of the study are as follows. First, the teacher uses an inspirational approach strategy through individual and classical stimulation to awaken and deepen routine and incidental emotional experiences so that children's feelings are touched so that creative images are formed through optimizing the emotional potential of students. This role can be played by the teacher, either at the beginning or in the learning process, especially when drawing is in progress. The teacher asks the students to express themselves on the picture with a free theme based on the student's choice of tools or crayons. Second, drawing by students show a good tendency for student creativity, it can be seen that various themes, holiday, aspirations, loved ones, joy, preferred activities, natural environment and so on. The drawing style is relatively the same, namely representative but not yet showing a perfect realistic level.

Keywords: emotion, creativity, visual arts, teacher 


\section{PENDAHULUAN}

Kecerdasan emosional dan kreativitas merupakan sebuah keterampilan utama dalam mendukung kesuksesan hidup seseorang. Ivcevic \& Hoffmann (2017) menjelaskan emosi berperan membantu seseorang melihat peluang terhadap masalah yang dihadapi untuk menjadi kreatif. Emosi merupakan bagian integral dari proses kreatif.

Emosi seperti ketidakpuasan atau kekecewaan dapat membantu seseorang menyadari bahwa ada kebutuhan untuk perubahan atau peluang untuk sukses. Emosi yang menyenangkan seperti kagum di pegunungan, atau senang dengan kelucuan seorang anak, juga dapat memotivasi seseorang untuk mengendapkan pengalaman itu dalam sebuah lukisan atau gambar. Emosi yang berupa perasaan menyenangkan, kebahagiaan dan perasaan tidak menyenangkan seperti kecemasan, traumatik dapat pula mendukung proses kreatif (Baas, De Dreu, \& Nijstad, 2008 ; Byron \& Khazanchi, 2011). Namun demikian, emosi tidak menyenangkan terkadang sering dipandang negatif dan dapat merusak kreativitas. Padahal emosi negatif maupun positif dapat berguna sebagai potensi untuk menghasilkan kegiatan kreatif. Hal yang paling penting adalah melakukan kontrol dan mengelola emosi. Semua emosi dapat dipandang sebagai sumber informasi dan potensi untuk pemikiran dan produksi kreatif, tergantung pada keterampilan seseorang dalam mengenali, memahami, dan menyalurkan emosi-emosi itu secara efektif (Beghetto dan Kaufman, 2007).

Namun yang masih menjadi persoalan adalah masih banyak tidak dipahami dan dimengerti bagaimana proses tindakan yang seharusnya dilakukan seorang guru agar seseorang dapat menyalurkan emosinya menjadi kegiatan yang kreatif. Pada konteks tersebut, salah satu kegiatan yang paling banyak digunakan untuk dapat mendukung peningkatan kreatif adalah kegiatan praktik berkarya seni visual. Proses pembelajaran seni rupa di SD merupakan kegiatan yang berfokus meningkatkan kepekaan emosional dan kreativitas. Winner dan Lancrin (2014) menegaskan keterlibatan dengan seni tidak hanya memupuk kreativitas artistik tetapi juga kreativitas seharihari dengan mendorong pemikiran kreatif dan pola pikir inovatif.

Emosi sangat penting diaktifkan sebagai sumber atau potensi energi dalam mengaktulisasikan proses kreatif agar dihasilkan karya seni yang bermakna bagi anak. Kreativitas anak merupakan kreativitas kecil-Little C yang berbeda dengan kreativitas sehari-hari, kreativitas tingkat profesional dan kreativitas paling tinggi (Sugiarto, 2019). Namun dalam realitas, anak-anak SD seringkali mengalami hambatan dalam mengungkapkan ide pikiran pada sebuah kegiatan menggambar. Anak tidak mampu menemukan tema yang ingin diekspresikan. Begitupula, anak tidak memiliki ketrampilan menorehkan garis-garis untuk mewujudkan apa yang ada dalam pikirannya. Beberapa anak mengalami hambatan dan kekacauan sehingga hal yang paling mudah dilakukan adalah menggambar berdasarkan bentuk yang ada atau imitasi terhadap hal yang sudah ada. Akibatnya dalam satu kelas terjadi gambar yang homogen atau memiliki tingkat kesamaan yang tinggi. Anak-anak SD seringkali mengungkapkan idenya dalam bentuk pemandangan sawah, flora dan fauna dalam komposisi yang ajeg atau tetap. Mereka mengalami kemonotonan dan kemandegan dalam mengungkapkan imajinasinya (Rengganis, 2011). Anak-anak memiliki emosi yang masih terpendam dan seringkali sulit ditelisik secara verbal. Mereka seringkali diam ketika ditanya guru. Akhirnya, sebagian besar guru mengalami hambatan dalam mendorong mereka. Padahal jika dieksplorasi, bentuk ungkapan visual anak sangat unik dan khas.

Di sisi lain, telaah teoretis tersebut telah memunculkan problematika baru yaitu perlunya kemampuan guru yang mampu menyiapkan strategi atau model pembelajaran yang efektif dalam rangka mengoptimalkan potensi emosi anak. Seorang guru harus mampu memberikan dorongan yang positif agar kecerdasan emosional anak dapat meningkat dan berguna untuk menyalurkan ide, mimpi, dan keinginan-keinginannya. Guru harus mampu membangun suasana kelas yang dapat menstimulus anak agar mampu mengenal, memahami, dan menyalurkan emosinya. Guru harus berperan meningkatkan kecerdasan emosi anak sehingga mereka memiliki keterampilan kreativitas artistik dalam berkarya seni visual. Emosi positif maupun negatif dalam tingkatan tertentu dari setiap anak perlu digali, dieksplorasi, dan diendapkan melalui guru agar endapan emosi dapat menghasilkan informasiinformasi, ide, mimpi, dan keinginan yang dapat berguna dalam proses kreatif. Namun kenyataannya, selama ini dapat dinyatakan bahwa sebagian besar guru hanya memiliki pengetahuan kognitif materi pembelajaran yang hanya melekat pada diri tetapi tidak mampu menjabarkan secara operasional atau aplikatif secara mandiri dan kreatif. Guru-guru pun hanya melaksanakan kurikulum yang bersifat instruksional tanpa mengkreatifkannya di lapangan (Rohidi, 2005: 91). Apalagi, jika tidak dijalinnya komunikasi antara satuan pendidikan yang lebih atas maka dimungkinkan banyak terjadi ketidakpahaman. Akhirnya tujuan awal pendidikan seni rupa yang telah ditetapkan bisa meleset dari harapan.Dalam konteks tersebut penelitian ini berusaha menyelidiki mekanisme penciptaan suasana dalam kelas yang dilakukan guru-guru sekolah dasar di Kota Semarang dalam upaya mengelola dan mengendapkan emosi anak agar menghasilkan karya yang kreatif.

\section{METODE}

Penelitian ini menggunakan pendekatan deskriptif kualitatif yang bersifat eksplanatoris. Strategi guru dalam 
pengoptimalan potensi emosi anak dalam pembelajaran menggambar dan hasil gambar anak dideskripsikan kualitatif disertai penjelasan yang lebih mendalam dan dinamis. Fokus amatan pada pembelajaran seni rupa di beberapa SD Kota Semarang. Wawancara mendalam dilakukan terhadap 15 guru SD Negeri di Semarang dengan masa mengajar bervariasi dari 5-40 tahun dan merepresentasikan tingkat kemajuan akademik SD. Pengalaman 5 tahun membuat guru berpengalaman menerapkan metode mengajar seni rupa dan memahami psikologi dan karakteristik anak. Observasi terhadap proses pembelajaran dan hasil gambar anak dapat menjelaskan informasi mengenai informasi strategi mengajar guru. Teknik analisis kualitatif diawali reduksi data, sajian data, dan diakhiri dengan penarikan kesimpulan. Ketiga komponen analisis tersebut aktivitasnya dilakukan dalam bentuk interaktif dan siklus (Miles \& Huberman, 1992). Secara lebih spesifik, analisis data berpedoman proposisi teoretis dan pengembangan deskripsi dilakukan kombinasi analisis domain dan eksplanasi. Analisis eksplanasi sangat diperlukan untuk membandingkan temuan analisis domain pada setiap kasus dengan kasus-kasus berikutnya agar semakin diperoleh penjelasan yang kuat dan holistik (Yin, 2008: 60-65).

\section{ANALISIS DAN INTERPRETASI DATA}

Penelitian dilaksanakan di beberapa SD Negeri di Kota Semarang terutama di Kecamatan Semarang Tengah, Gajahmungkur, Banyumanik. Guru-guru mengajar dalam kondisi SD yang memiliki sarana dan prasarana memadai dan berkategori akademik baik. Guru memiliki latar belakang Pendidikan Guru Sekolah Dasar (PGSD). Sebelum kurikulum 2013, SD menerapkan Kurikulum Tingkat Satuan Pendidikan (KTSP). Pembelajaran seni rupa merupakan satu kesatuan dengan pembelajaran seni tari, musik dan teater serta keterampilan yang pelaksanaannya dilakukan secara bergantian. Pada KTSP Pembelajaran SBK (Seni Budaya dan Keterampilan) terpisah dengan mata pelajaran lain. Sedangkan pada kurikulum 2013, pembelajaran SBK terintegratif dengan mata pelajaran lain dalam ikatan sebuah tema tertentu.

Secara konsep tidak ada perbedaan pembelajaran seni rupa di SD baik pada KTSP maupun Kurikulum 2013. Pendidikan seni rupa bertujuan meningkatkan kepekaan emosional dan kreativitas anak didik. Pembelajaran seni rupa mencakupi penguasaan kompetensi psikomotorik, afektif, dan kognitif yang diimplementasikan dalam pembelajaran apresiasi dan kreasi. Pembelajaran dilakukan dengan kegiatan berkarya seni yang d iantara proses dan selesainya akan disertai kegiatan apresiasi. Kegiatan kreatif lebih banyak didominasi menggambar dibandingkan membentuk, menganyam, berkarya kolase, mozaik, montase, mematung, menghias, dan membuat kerajinan.
Guru-guru yang dilibatkan sebagai informan dalam penelitian ini berjumlah 15 orang. Mereka dalam membelajarkan seni rupa telah berpengalaman dengan menggunakan acuan kurikulum KTSP dan Kurikulum 2013. Guru telah melakukan pengelolaan komponen pembelajaran yang mencakupi tujuan, metode, bahan, dan evalusi dengan menuangkan pada Silabus dan Rencana Pembelajaran (RPP). Guru dalam setiap pembelajaran berpedoman RPP. Pembelajaran menggambar terdiri tahapan kegiatan pembukaaan, kegiatan inti, dan kegiatan penutup sebagai berikut.

\section{Kegiatan Awal}

Kegiatan pembuka dilaksanakan 10-20 menit. Diawali sapaan guru, dilanjutkan ulasan sekilas materi yang akan disampaikan. Kegiatan ini bertujuan agar anak lebih siap menerima pembelajaran sehingga dapat lebih menangkap materi pembelajaran. Sebelum praktik menggambar, guru mendeskripsikan tema dan membawa beberapa contoh gambar karya. Aktivitas guru memiliki varian sebagai berikut. Guru menginformasikan kualitas contoh gambar karya berdasarkan aspek kelebihan dan kekurangan. Ada guru yang meminta siswa melihat lingkungan sekitar sekolah dalam rangka memberikan pemahaman kondisi alam seutuhnya. Ada pula guru yang meminta anak untuk merespon pengalaman pribadi sebagai misal liburan, suasana keluarga, cita-cita, kegiatan yang paling disukai dan selanjutnya. Selanjutnya guru membuka diskusi sederhana mengenai gambar tersebut. Diskusi meliputi tema gambar dan relasi subjek-subjek gambar. Beberapa guru juga meminta anak merefleksi pengalaman pribadinya untuk dituangkan dalam gambar. Hal ini bertujuan agar siswa menjadi lebih dapat mendapatkan ide untuk proses berkarya dan siswa merasa lebih bersyukur atas karunia nikmat alam yang diberikan oleh Tuhan kepada manusia.

\section{Kegiatan Inti}

Kegiatan pembuka dilaksanakan 30-50 menit. Guru menginstruksikan kepada siswa untuk menggambar. Metode pembelajaran bervariasi mulai ceramah, tanya jawab, demonstrasi. Guru mendemonstrasikan langkahlangkah kegiatan menggambar, mulai (1) mempersiapakan bahan dan alat, (2) mensket subjek gambar (3) menambahkan beberapa subjek pendukung agar tema gambar semakin dapat teraktualisasikan, (4) menentukan warna-warna dalam subjek gambar yang akan diwarnai, (3) memilih warna yang akan digunakan, (4) menggoreskan warna pada gambar dengan rapi, dan (5) setelah gambar selesai diwarnai, alat berkarya dirapikan dan dikembalikan ke tempat semula. Beberapa siswa memiliki kelancaran menuangkan ide. Siswa yang kesulitan dibimbing guru dengan cara memotivasi, menginspirasi dengan bercerita agar anak tergali ide baik dari pengalaman pribadi maupun dari perasaan emosional anak sekaligus memotivasi. Beberapa guru menggunakan media pembelajaran berupa tayangan LCD, memnggambar langsung pada kertas, 
dan papan tulis. Pada proses kegiatan menggambar, guru juga melakukan aktivitas tanya jawab pada saat siswa mengerjakan gambar. Kegiatan ini ditujukan untuk memantapkan agar proses kegiatan menggambar dapat menghasilkan gambar yang berkualitas di samping untuk mengetahui kelebihan dan kekurangannya. Sesekali dalam proses pembelajaran, guru juga mengarahkan agar siswa menggores dan mewarnai yang benar. Kegiatan ini mengasah siswa dalam memperoleh pengalaman estetik secara empiris melalui pengalaman menggambar. Siswa akan menjadi lebih bersemangat ketika gambarnya sering dikoreksi dan diberi masukan-masukan agar dapat dihasilkan karya yang lebih berkualitas.

\section{Kegiatan Penutup}

Kegiatan pembuka dilaksanakan 10-20 menit. Kegiatan penutup diisi simpulan setelah siswa menyelesaikan gambarnya. Pada akhir pembelajaran, siswa mengumpulkan karya masing-masing kemudian siswa diminta memberi tanggapan atas karya yang telah dihasilkan. Tanggapan siswa beragam, mulai dari yang sangat antusias kemudian menceritakan dengan detail subjek gambar dan menyatakan kekaguman atau kekurangan karya sampai siswa yang sangat pasif dalam menilai kualitas gambar. Guru senantiasa mengajak siswa untuk dapat mengapresiasi karya-karya yang telah dihasilkan mulai dari aspek kelebihan dan kekurangan karya. Kegiatan apresiasi seperti ini juga bertujuan untuk menguatkan ingatan siswa akan apa saja yang telah siswa lakukan dalam pembelajaran sekaligus menanamkan sikap. Guru akan memberikan pertanyaan kepada siswa. Hal ini juga membantu guru dalam menentukan apakah pembelajaran telah berhasil atau masih perlu perbaikan.

Berdasarkan temuan data, hampir semua guru telah membelajarkan kegiatan berkreasi gambar dengan menggunakan pendekatan inspiratif untuk menggali ide anak. Pendekatan inspiratif dilakukan secara klasikal dan individual. Hanya beberapa saja guru yang menggunakan cara individual. Langkah yang dilakukan guru untuk menstimulus ide anak dengan cara bercerita, memberikan model atau contoh gambar, meminta anak merenungkan pengalaman pribadi, dan meminta anak memperhatikan, mengobservasi, dan merefleksi temuan di luar kelas. Temuan-temuan itu diharapkan mampu direfleksi, diendapkan, sehingga menjadi ide yang mulai mengkristal (Sumardjo, 2000). Hal tersebut terlihat bagaimana seorang guru terus mendampingi anak dalam menggamabar baik saat kegiatan awal mamupun kegiatan inti berlangsung.

Pendekatan inspiratif secara klasikal dan individual berhasil mendorong anak untuk menemukan ide berkarya. Keberhasilan menstimulus anak menemukan ide karena anak-anak relatif memiliki semangat dan sedang dalam kondisi perasaan yang senang atau bahagia. Namun dalam kenyataannya, pendekatan tersebut tidak berhasil membantu kasus anak yang kesulitan dalam menggambar dengan faktor penyebab bukan karena tidak memiliki motivasi akan tetapi sedang mengalami kondisi emosi yang tidak sedang bahagia atau sedih.

Guru hanya mendorong anak untuk semangat menggambar namun tidak memiliki kesadaran bahwa kesedihan merupakan potensi emosi yang memungkinkan digunakan modal menstimulus ide menggambar. Guru kurang memiliki tindakan untuk mendorong potensi emosi yang sedang sedih tersebut untuk dituangkan sebagai karya gambar. Masih banyak anggapan pada guru bahwa tema gambar harus selalu menggambarkan sebuah narasi kebahagian, pemandangan, alam benda, atau pun kegiatankegiatan yang disukai.

Mayer \& Salovey (1997) menyatakan bahwa guru tidak mampu melakukan aktivitas tindakan berupa observing emotion in art and transforming emotion in art making. Hal tersebut terlihat pada saat kegiatan awal menggambar, guru tidak pernah memberikan contoh sebuah gambar yang ber-subject matter kesedihan. Guru kurang memberikan contoh alternatif melalui model LCD berupa karyakarya seni yang menggambarkan suasana kegelisahan, kesedihan, kemarahan, ketakutan dan lain sebagainya.

Selain itu, guru tidak memiliki kesadaran untuk mengidentifikasi emosi anak yang sedih dan menggunakan kesedihan itu sebagai problem solving atas berhentinya ide menggambar. Anak-anak tidak diberikan peluang mengungkapkan perasaan kesedihan dalam sebuah gambar abstrak atau meluapkan warna dalam bentuk yang tidak berwujud. Dalam beberapa wawancara dengan guru dapat disimpulkan bahwa anak-anak yang tidak mau menggambar dianggap kurang berbakat dan anak yang sedang mengalami kondisi emosi sedih atau traumatis dipersepsi oleh guru akan mengalami kesulitan dalam menggambar. Hal tersebut sesuai dengan yang dinyatakan oleh seoarang Guru SD Negeri Ngijo, Kustinono sebagai berikut.

"Anak-anak yang sulit menggambar biasanya tidak memiliki bakat. Mereka tidak bisa menuangkan ide dan mewarnai secara aktif karena biasanya sedang mengalami masalah sehingga perasaannya ikut terbawa larut dalam kesedihan. Anak tersebut ketika diminta menggambar akan sulit dan cenderung menghasilkan gambar yang tidak akan selesai dan sempurna. Mereka mengalami kesulitan untuk menuangkan ide"

Anak-anak yang dalam kondisi kesulitan menggambar tidak mendapatkan metode inspiratif dari guru secara individual dan mendalam. Akhirnya guru sulit untuk memahami emosi anak atau understanding emotion children (Mayer \& Salovey (1997). Guru tidak melakukan pendampingan dalam tingkat yang lebih mendalam terutama mengenai penyebab dan konsekuensi perasaan kesedihan itu dalam tingkat pribadi dan keterkaitannya dengan pribadi lainnya. Jika guru merefleksi pengalaman itu, bagaimana mengelola pengalaman itu, dan bagaimana 


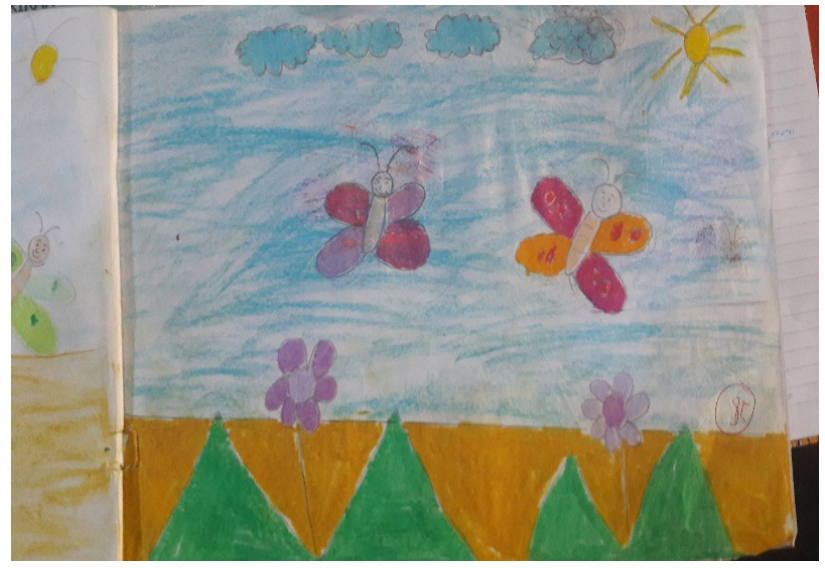

Gambar 1. Kreativitas anak kelas 1 SD yang telah mengekspresikan emosi kebahagian dalam gambar bertema alam dan kupu-kupu

mengendapkan pengalaman itu sehingga hasil endapan emosi itu setidaknya akan berpeluang menjadi ide sekaligus tema gambar.

Sebagian besar guru telah mampu melakukan pendekatan inspiratif tersebut bagi anak yang sedang dalam kondisi bahagia. Menurut Sumardjo (2020), guru telah mampu memiliki kompetensi dalam mendorong anak untuk dapat mengamati, menggunakan, memahami emosi perasaaan bahagia, mengelola emosinya dalam tujuan kreatif. Guru SD secara intensif telah mendampingi proses menggambar anak secara kreatif.

Temuan yang menarik perhatian dalam penelitian ini adalah guru kurang memiliki kepekaan untuk menghadirkan tema gambar yang khusus merujuk suasana kebahagian. Kebahagian rata-rata dimunculkan hanya pada narasi visual sebuah ilustrasi pemandangan alam, pemandanga kota, flora dan fauna atau kegiatan sehari hari. Masih sedikit perlakukan guru yang meminta anak untuk menghadirkan suasana kebahagian dalam bentuk ungkapan bebas ekspresif berupa goresan warna dengan bentuk-bentuk non representatif.

Karakteristik gambar anak yang sedang dalam emosi bahagia akan cenderung dapat terselesaikan. Garis membentuk subjek figur yang lebih sempurna. Bidangbidang subjek telah terwarnai secara merata. Perbentukan berorientasi dalam ungkapan corak realistik dengan goresan garis dan goresan warna yang tertata rapi Kreativitas gambar yang dihasilkan menunjukkan subjek dan pewarnaan yang sudah sempurna dan selesai. Perbentukan subjek gambar sudah terwujud dan memiliki pesan yang ingin disampaikan secara jelas. Gambar menunjukkan kekuatan komposisi yang relatif harmonis dan seimbang. Hal tersebut didukung penataan subjek gambar yang tertata baik, garis arsir dan kontur figur yang cenderung rapi.

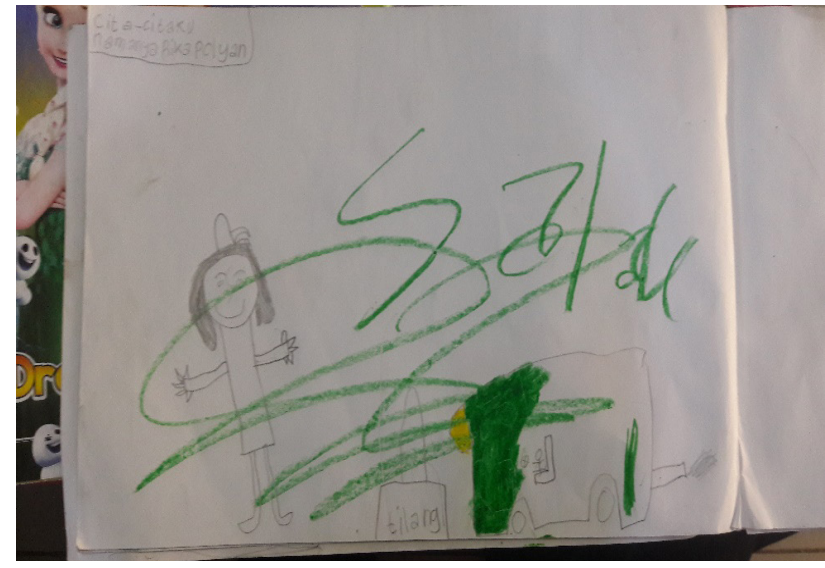

Gambar 2. Kreativitas anak yang sedang mengalami emosi sedih relatif kesulitan menyelesaikan gambar.

Anak yang sedang mengalami masalah kesulitan dalam menggambar dan hasil gambarnya kurang optimal. Kreativitas gambar menunjukkan subjek dan pewarnaan yang belum sempurna dan belum selesai. Perbentukan subjek gambar mulai terwujud namun belum tuntas narasi yang ingin disampaikan. Namun kelebihan gambar anak tersebut dari sudut pandang pendekatan ekpresivisme, gambar menunjukkan kekuatan ekspresi garis yang kuat tetapi cenderung acak, asal, tidak serius dan belum menunjukkan selesai (Feldman, 1967).

\section{SIMPULAN}

Hasil penelitian menunjukkan bahwa sebagian besar guru menggunakan strategi pendekatan inspiratif melalui stimulasi individual dan klasikal untuk memunculkan ide anak dalam menggambar. Pendekatan inspiratif lebih didominasi dilakukan untuk membangun dan memperdalam pengalaman emosional rutin atau isidental anak yang sedang berbahagia. Sebagian besar guru kurang memiliki kesadaran dan kurang memiliki tindakan khusus dalam menstimulus anak yang sedang bermasalah dan mengarahkan potensi emosi kesedihan itu untuk menjadi ide yang divisualisasikan dalam gambar. Hasil gambar anak yang sedang berbahagia menunjukkan kecenderungan kreativitas gambar yang baik. Terlihat pada tema yang bervariasi (liburan, cita-cita, orang yang disayang, kegiatan yang disukai, lingkungan alam), perbentukan yang realistik, perwarnaan yang rapi dan memenuhi bidang perbentukan figur atau subjek lainnya secara rata dan rapi. Sedangkan gambar anak yang sedang mengalami masalah atau sedih menunjukkan belum sempurna dan tuntas akan tetapi goresan garis dan warna cenderung kuat dan spontan.

\section{DAFTAR RUJUKAN}

Baas, M., De Dreu, C. K. W., Nijstad, B. A. 2008. “A metaanalysis of 25 years of mood-creativity research: Hedonic 
tone, activation, or regulatory focus?" Psychological Bulletin, 134(6), 779-806. doi:10.1037/a0012815

Beghetto, R. A., Kaufman, J. C. 2007. "Toward a broader conception of creativity: A case for "mini-c" creativity". Psychology of Aesthetics, Creativity, and the Arts, 1, 7379. doi:10.1037/1931-3896.1.2.73

Beghetto, R. A., \& Kaufman, J. C. 2011. Teaching for Creativity with Disciplined Improvisation. In Sawyer R. K. (ed.). Structure and Improvisation in Creative Teaching . pp. 94 109. New York: Cambridge University Press

Brenner, E. M., \& Salovey, P. 1997. Emotional regulation during childhood: Developmental, interpersonal, and individual considerations. In P. Salovey \& D. J. Sluyter (Eds.), Emotional development and emotional intelligence: Educational implications (pp. 168-195). New York: Harper Collins.

Byron, K. and Khazanchi, S. 2011. "A meta-analytic investigation of the relationship of state and trait anxiety to performance on figural and verbal creative tasks". Personality and Social Psychology Bulletin, 37, 269-283. doi:10.1177/0146167210392788.

BSNP. 2006. Panduan Penyusunan Kurikulum Tingkat Satuan Pendidikan Jenjang Pendidikan Dasar dan Menengah. BSNP: DEPDIKNAS.

Csikszentmihalyi, M. 1988. "Motivation and creativity: Toward a synthesis of structural and energistic approaches to cognition". New Ideas In Psychology, 6(2), 159-176.

Darsono, 2000. Belajar dan Pembelajaran. Semarang: IKIP Press

Feldman, E.B. (1967). Art as Image and Idea. New Jersey: Prentice-Hall, Inc., Englewood Cliffs.

Goleman D. 1997. Kecerdasan Emosional: Mengapa EI Lebih Penting Daripada IQ. Heryana T, penerjemah. Jakarta (ID): PT Gramedia Pustaka Utama.

Iryanti dan Jazuli. 2001. Mempertimbangkan Konsep Pendidikan Seni. Semarang: FBS Unnnes

Ivcevic, Z. and Hoffmann, J. D. 2017. "Emotions and creativity: From states to traits and emotion abilities". In Feist, G., Reiter-Palmon, R., Kaufman, J. C. (Eds.), Cambridge Handbook Of Creativity And Personality Research (pp. 187-213). New York: Cambridge University Press.

Plucker, J. A., Beghetto, R. A., Dow, G. T. 2000. "Why isn't creativity more important to educational psychologists? Potentials, pitfalls, and future directions in creativity research". Educational Psychologist, 39, 83-96. doi:10.1207/s15326985ep3902_1

Rengganis, I. 2011. Analisis Gambar Karya Anak Sekolah Dasar (Karakteristik Gambar Anak Usia 7 - 9 Tahun) dalam Jurnal Ilmu pendidikan Vol 15 No. 1 2017. FIP Universitas Pendidikan Indonesia.

Rohidi, T.J., 2005, “Menegaskan Seni Ketika Pendidikan Menafikannya: Refleksi Budaya Tentang Manusia Seutuhnya Dalam Konteks Masyarakat Bhinneka Tunggal Ika" dalam Rampaian Orasi Ilmiah Guru Besar Universitas Negeri Semarang dalam Dies Natalis ke 41, Semarang: UNNES Press.

Rosyada, D., 2007, Paradigma Pendidikan Demokratis: Sebuah Model Pelibatan Masyarakat dalam Penyelenggaraan Pendidikan. Jakarta: Kencana

Russ, S. W., Grossman-McKee, A. 1990. "Affective expression in children's fantasy play, primary process thinking on the Rorschach, and divergent thinking". Journal of Personality Assessment, 54, 756-771. doi:10.1207/s15327752jpa5403\&4_28

Russ, S. W., Grossman-McKee, A. 1999. Affective expression in children's fantasy play, primary process thinking on the Rorschach, and divergent thinking. Journal of Personality Assessment, 54, 756-771. doi:10.1207/ s15327752jpa5403\&4_28

Martin, L. L., Ward, D. W., Achee, J. W., \& Wyer, R. S. 1993. Mood as input: People have to interpret the motivational implications of their moods. Journal of Personality and Social Psychology, 64(3), 317-326. https://doi. org/10.1037/0022-3514.64.3.317.

Mayer, J. D., \& Salovey, P. 1999. "What is emotional intelligence?" In P. Salovey \& D. J. Sluyter (Eds.), Emotional development and emotional intelligence: Educational implications (pp. 3-34). New York: Harper Collins.

Salam, Sofyan. 2001. Pendidikan Seni Rupa di Sekolah Dasar. Makasar: Universitas Negeri Makasar.

Salovey P and Mayer J. 1990. Emotional Intellidence. Imagination, cognition, and personality, 9(3), 185-21.

Sugandi, A. \& Haryanto, 2004. Teori Pembelajaran. Semarang: UPT MKK Unnes

Sudjana. 2000. Dasar-Dasar Proses Belajar Mengajar. Bandung: Sinar Baru Algensido

Sugiarto, Eko. 2019. Kreativitas, Seni dan Pembelajarannya. Yogyakarta: LKiS 
Sumardjo, J. 2000. Filsafat Seni. Bandung: ITB Press

Susanto, E. 2017. "Budaya Kreatif dalam Konsep dan Pengembangan" Journal of Multicultural Studies in Guidance and Counseling Vol 1(2) Departemen Psikologi Pendidikan dan Bimbingan UPI Bandung

Syafii, 2006. "Konsep dan Model Pembelajaran Seni" dalam Handout Jurusan Seni Rupa FBS Universitas Negeri Semarang

Winner, E., Goldstein, T. R., Vincent-Lancrin, S. 2014. "Does arts education foster creativity?" The evidence so far. In L. O'Farrell, S. Schonmann, \& E. Wagner (Eds.), International yearbook for research in arts education (Vol. 2, pp. 95-100). Hong Kong: Waxmann Verlag.

Yin, Robert K. 2008. Studi Kasus: Desain dan Metode, diterjemahkan M Djauzi Mydzakir. Jakarta: PT Raja Grafindo Persada. 